\title{
TYROPHAGUS PUTRESCENTIAE (SCHRANK) (ACARI: ACARIDAE) FROM WESTERN IRAN WITH A KEY TO IRANIAN SPECIES OF THE GENUS
}

\author{
Bahman Asali Fayaz, Mohammad Khanjani ${ }^{1 *}$ and Hassan Rahmani² \\ 'Department of Plant Protection, College of Agriculture, Bu-Ali Sina University, Hamedan, \\ Iran \\ ${ }^{2}$ Department of Plant Protection, College of Agriculture, Zanjan University, Zanjan, Iran \\ *Corresponding author: mkanjani@gmail.com
}

\begin{abstract}
This paper reports the redescription of all stages (egg, immatures and adult) of the mold mite, Tyrophagus putrecentiae (Schrank 1781), collected from bean leaves infested with opportunity fungus in the Department of Plant Protection laboratory, Hamedan, Iran.
\end{abstract}

KEY WORDS: Acari, Sarcoptiformes, Tyrophagus, redescription, key.

DOI: 10.21684/0132-8077.2016.24.1.61.76

\section{INTRODUCTION}

The family Acaridae (Acari: Sarcoptiformes) is a large cosmopolitan group including more than 90 genera and about 400 described species (Fan and Zhang 2007). The genus Tyrophagus was erected by Oudemans, 1924a with type species Acarus putrescentiae Schrank, 1781. Up to now about 35 species of the genus Tyrophagus Oudemans were recorded from around the world (Fan and Zhang 2007), eight species of the genus have been recorded from Iran (Khanjani et al. 2000; Kamali et al. 2001; Hadad Iraninezhad et al. 2007; Lotfollahi et al. 2010), namely: T. brevicrinatus Robertson, 1959; T. longior (Gervais 1844); T. neiswanderi Johnston and Bruce, 1965; T. vanheurni Oudemans, $1924 \mathrm{~b}[=$ T. palmarum $\mathrm{Ou}-$ demans; sensu Robertson, 1959 (Fan and Zhang, 2007); T. perniciosus Zakhvatkin, 1941; T. putrescentiae (Schrank, 1781); T. similis Volgin, 1949; T. zachvatkini Volgin, 1948. Mold mites, T. putrescentiae, are well-known and treated as one of the most common, economical, cosmopolitan and polyphagous mites of agricultural (Chmielewski 1999) and medical importance (Klimov and OConnor 2009). Currently there is a disagreement on the concept of $T$. putrescentiae (Schrank, 1781) and T. communis Fan and Zhang, 2007 between Klimov and OConnor $(2009,2010)$ and Fan and Zhang (2014). In this study the concept of $T$. putrescentiae was followed but with circumspection. Furthermore, a key to Iranian species of the genus Tyrophagus is presented, based on the literature. In addition, the comparison of characters of adult and immatures (larva, protonymph and tritonymph) stages of T. putrescentiae is provided in Table 1.

\section{MATERIAL AND METHODS}

All specimens were collected from bean leaves infested with opportunity fungus. The mites were mounted directly in Hoyer's medium on microscope slides. The slides were dried in an oven $\left(50^{\circ} \mathrm{C}\right)$, sealed with industrial painting material, and examined with an Olympus BX51 Differential Interference Contrast (DIC) microscope. Drawings were made with a camera lucida. All measurements are presented in micrometers $(\mu \mathrm{m})$. The terminology and abbreviations of idiosomal chaetotaxy used follows that of Griffiths et al. (1990); Grandjean (1939) for leg chaetotaxy; organotaxy complies with Klimov and OConnor (2003).

Acaridae Latreille, 1802

Tyrophagus Oudemans, 1924

(Oudemans 1924a: 250).

Type species: Acarus putrescentiae Schrank, 1781.

Tyrophagus putrescentiae (Schrank, 1781)

Female (Figs. 1-12; $\mathbf{n}=7$ ). Idiosoma oval. Length of body including gnathosoma 578-700, excluding gnathosoma 485-580; width 300-350.

Dorsum (Figs. 1, 2, 5). Prodorsal shield punctate, with two pairs of setae ( $v i$ and ve) almost pentagonal in shape with lateral margins a slightly concave; 76-85 long, 90-95 wide between setae $v e-v e$. Eyespots present in lateral position of prodorsal shield ( 17-20 in diameter) (Figs. 1-2); Basal lobe of Grandjean's organ with one large tooth and two small teeth, 15-20, 5-8, and 3-5 long, respectively (Fig. 5). Supracoxal seta $s c x$ pectinated with six branches on each side and broadly expanding from the base but gradually tapers to a 
B. A. Fayaz, M. Khanjani and H. Rahmani

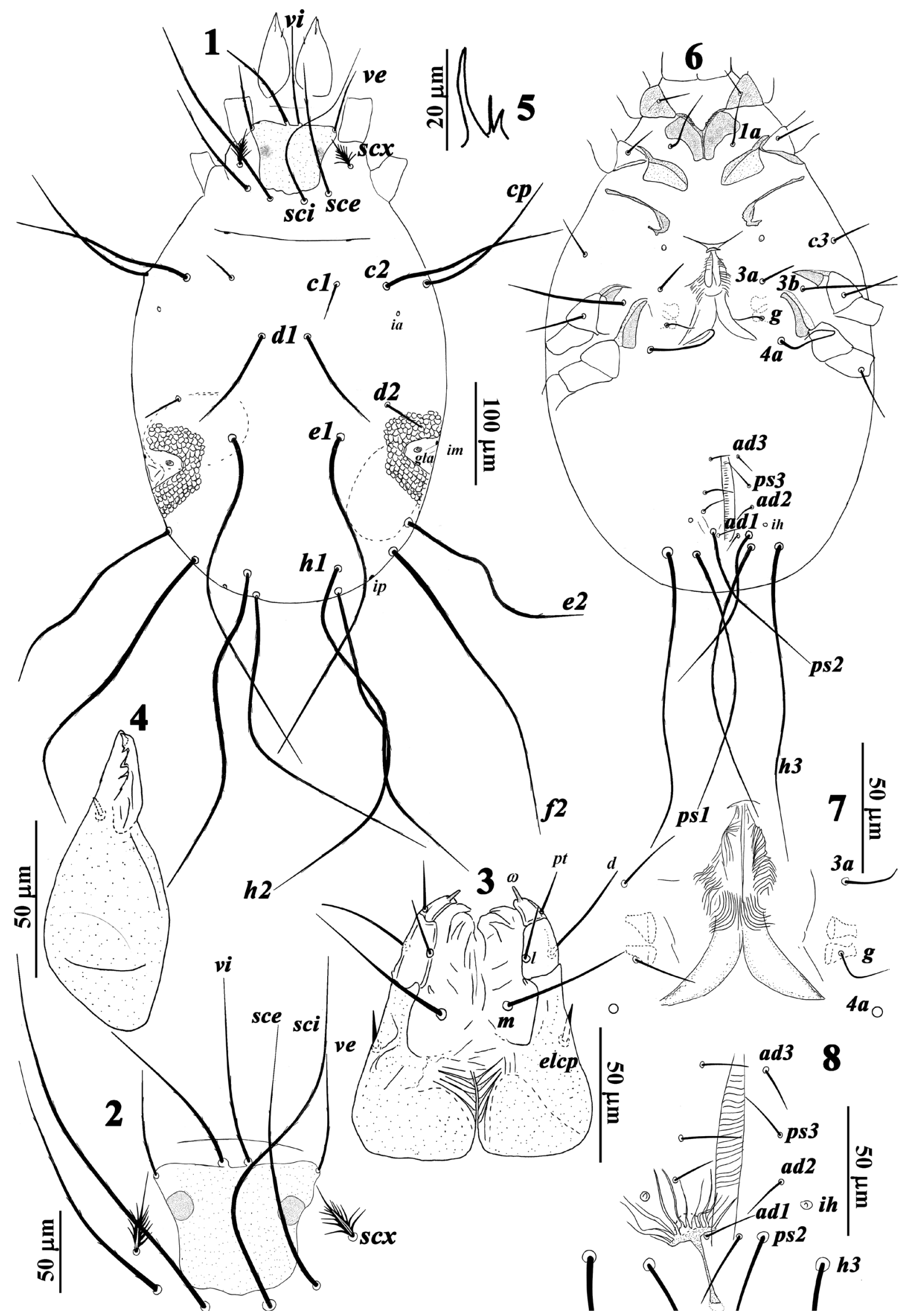

Figures 1-8. Tyrophagus putrescentiae (Schrank, 1781) (female): 1. Dorsal view; 2. Prodorsal shield; 3. Gnathosoma; 4. Chelicera; 5. Grandjean's organ; 6. Ventral view; 7. Genital region; 8. Anal region, copulatory opening and spermatheca. 
fine point distally (Fig. 2). All dorsal setae finely serrated. All opisthosomal setae whip-like except $c 1, d 1$, and $d 2$. Opisthosoma with three pairs of lyrifissures ( $\mathrm{ia}$, $\mathrm{im}$ and $\mathrm{ip}$ ) and one pair of opisthosomal gland ( $g l a)$ at level of seta $e 1$; seta $c l$ is the shortest and setae $e 1, f 2, h 1$, and $h 2$ are the longest dorsal setae; length of dorsal setae: vi 94-100; ve 55-65; sci 180-225; sce 101-130; scx 35-45; cl 30-42; c2 210-230; cp 168-200; d1 91-130; d2 42-50; e1 325-340; e2 220-250; f2 320-350; h1 320-360; h2 335-370. Distances: vi-vi 10-15; vive 35-42; ve-ve 82-100; ve-scx 42-50; scx-scx 125-140; scx-sce 32-40; sce-sce 90-102; sci-sce 25-40; sci-sci 30-35; sci-cl 90-110; cl-cl 110150; $c 1-c 2$ 58-70; $c 2-c 2$ 230-270; $c 2-c p$ 35-50; $c p-c p$ 300-340; $c 1-d 170-80 ; d 1-d 135-50 ; d 1-d 2$ 120-130; d2-d2 240-270; d2-e2 140-160; d2-gla 65-82; gla-gla 260-300; d2-el 60-80; e1-el 120-150; e1-e2 120-145; e2-e2 250-290; e2-f2 35-45; f2-f2 190-230; el-h1 150-165; h1-h1 95-100; h1-h2 25-50; h2-h2 80-90. Ratio: d1/cl 3.03-3.1; d1/d2 2.17-2.60; d2/c1 1.2-1.4.

Gnathosoma (Figs. 3-4). Punctate; palpi twosegmented, palp tarsus with a simple seta $(p t)$ and one solenidion $(\omega)$ 12-15 and 4-6 long, respectively; palp tibia with two simple setae $(d$ 25-30 and $l 15-20 \mathrm{long}$ ); infracapitulum with one simple seta $(m)$ 28-40 long (Fig. 3); Chelicerae 85-95 long, cheliceral seta cha spine-like 5-7 long, movable and fixed digits with 2-4 teeth (Fig. 4). Palp coxa with one elcp setae 10-13 (Fig. 3). Distance: $m-m$ 12-20.

Venter (Figs. 6-8). Coxal plates I divided with apodemes I anteriorly on each side with five nodules; coxal plates II broadly triangular and with a well-developed apodeme near base of trochanter seta; between coxae II and III a pair of thin sclerotized sejugal apodemes; coxal plates III-IV each with apodemes (Fig. 6); genital region (posterior to sejugal apodemes to coxae IV) with two pairs of genital papillae, a pair of setae $(g)$, and genital folds (Fig. 7). Anal region with three pairs of adanal setae $(a d 1-3)$ and three pairs of pseudoanal setae (ps1-3), seta $p s 1$ the longest anal setae (Fig. 6); a pair of lyrifissures $(\mathrm{ih})$ posterior to seta $a d 2$. Copulatory opening (7-10 in diameter) located posterior to anal opening, spermathecal duct (25-40 long) joins base of spermathecal sac (Fig. 8); length of ventral setae: $1 a$ 55-60, c3 30-35, 3a 27-38, 3b 95-110, 4a 90-100, g 25-30, ad3 15-22, ad2 1722, ad1 15-22, ps3 25-31, ps2 130-150, ps 1 230-270, h3 280-300. Distances: 1a-1a 60-70, $1 a-3 a$ 120-140, 3a-3a 95-135, 3a-3b 35-60, g-g
90-125, g-4a 28-35, 4a-4a 130-160, ad3-ad3 22-44, ad3-ps3 25-32, ps3-ps3 45-60, ps3-ad2 20-30, ad2-ad2 40-65, ad2-ad1 31-51, ad1-ps2 12-20, ps2-ps2 30-55, ps2-ps1 20-35, ps1-ps1 60-85, ps 1-h3 25-45, h3-h3 120-150.

Legs (Figs. 9-12). Setal formulae of leg segments I-IV as follows (solenidia and special setae in parentheses): coxae $1-0-2-1$; trochanters $1-$ $1-1-0$; femora $1-1-0-1$, genua $2(2 \sigma)-2(1 \sigma)$ $1(1 \sigma)-0$; tibiae $2(1 \varphi)-2(1 \varphi)-1(1 \varphi)-1(1 \varphi)$; tarsi $13(3 \omega, 1 \varepsilon)-12(1 \omega)-10-10$. Solenidion $\omega 1$ cylindrical, with apex slightly widened (figs. 9-12). Measurements of leg segments and setae as follows: Leg I 220-250: Tr 35-40, pR 38-45, Fe 50-60, vF 45-55, Ge 35-40, cG 40-47, mG 45-50, o1 46-50, б2 25-28, Ti 30-35, gT 38-45, hT 43-

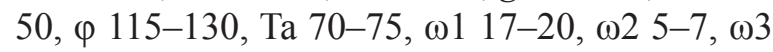
22-26, ع 3-5, a a 25-30, ba 25-33, wa 40-50, ra 30-40, la 25-30, d 40-50, e 5-8, f 15-20, p 4, q 5, $s$ 5-6, u 4-5, v 5, empodium 15-20, claw 10-14; Leg II 200-237: Tr 30-35, $p R$ 40-45, Fe 40-55, $v F$ 60-73, Ge 35-44, cG 33-40, $m G$ 42-50, $\sigma$ 20-24, Ti 30, gT 40-48, hT 40-50, $\varphi$ 120-130, Ta 65-70, $\omega$ 20-22, ba 24-30, wa 33-40, ra 30-35, la 20-28, d 40-45, e 4-5, f 14-20, p 4, q 4, s 6, u 4-5, $v$ 4-5, empodium 14-20, claw 10-12; Leg III 212-245: Tr 35-40, $p R$ 45-60, Fe 40-50, Ge 32-40,

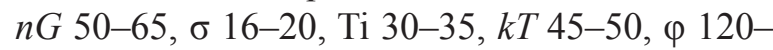
125, Ta 75-80, w 30-40, r 28-33, d 35-44, e 5, $f$ 30-35, p 3-4, q 3-4, s 5, u 4, v 4, empodium 14-18, claw 10-15; Leg IV 239-270: Tr 35-42, Fe 45-50, Ge 44-50, Ti 35-43, kT 40-53, $\varphi$ 110-120, Ta 80-85, w 35-40, r 25-32, d 36-40, e 5, f 28-32, p 3-4, q 3-4, s 5, u 4, v 4, empodium 12-17, claw 10-12; Ge and Ti IV with minute preapical process (Fig. 10).

Male (Figs. 13-24; $\mathbf{n}=\mathbf{5}$ ). Idiosoma oval, length of body including gnathosoma 520-630, excluding gnathosoma 420-540; width 240-310.

Dorsum (Figs. 13-16). Prodorsal shield punctate, with two pairs of setae ( $v i$ and ve) nearly pentagonal in shape with lateral margins slightly concave; 78-87 long, 90-100 wide between setae $v e-v e$. Eyespots present on lateral margin of prodorsal shield ( 15-17 in diameter) (Figs. 13, 16); Basal lobe of Grandjean's organ with one large tooth and three small teeth, 13-18, 6-7 and 4-5 long, respectively (Fig. 15). Supracoxal seta $s c x$ pectinated with six branches on each side (Fig. 14). All dorsal setae finely serrated. All opisthosomal setae whip-like except $c l, d l$ and $d 2$. Opisthosoma with three pairs of lyrifissures ( $i a, i m$ and $i p$ ) and one pair of opisthosomal glands (gla) at level of 
B. A. Fayaz, M. Khanjani and H. Rahmani

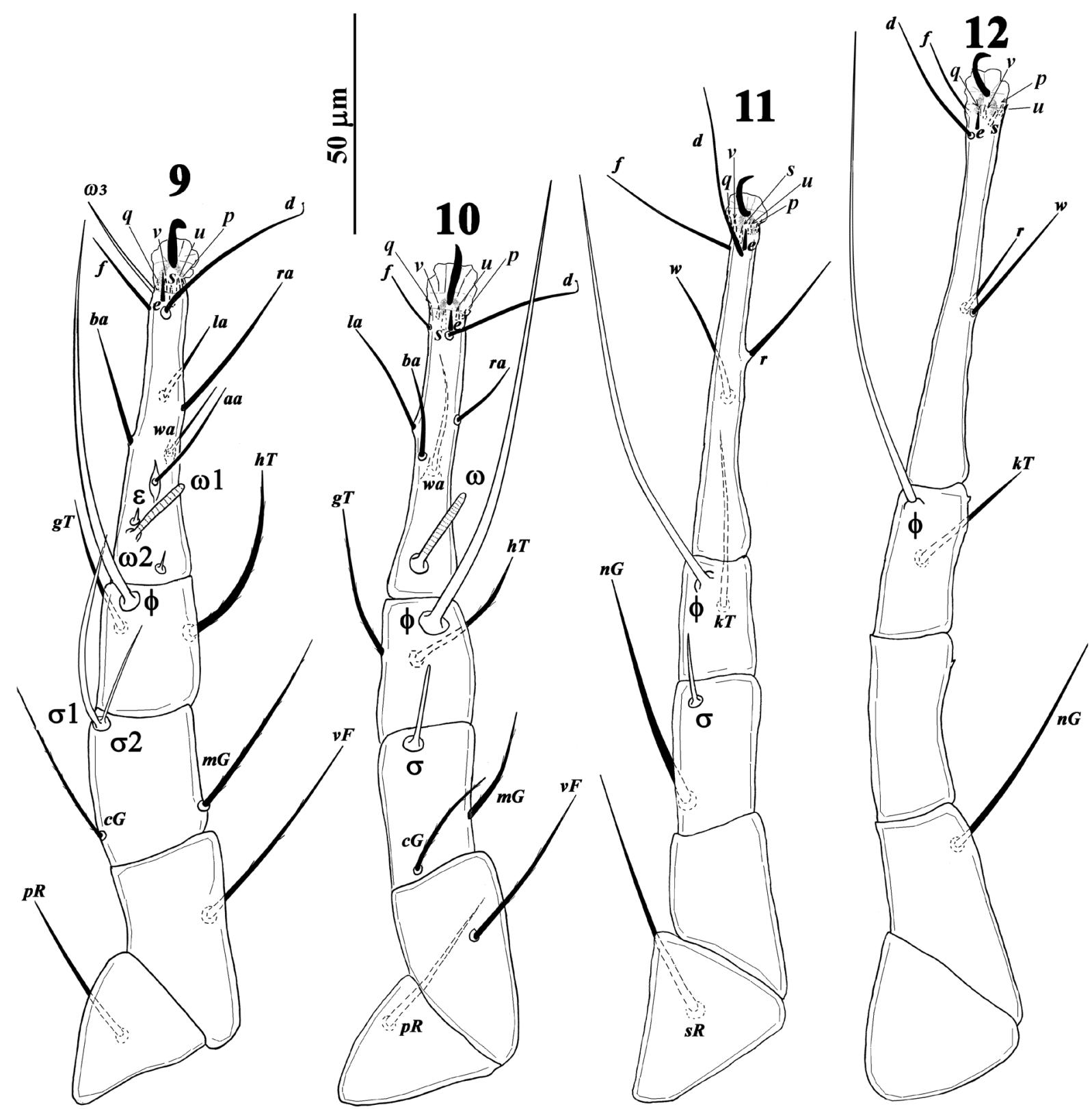

Figures 9-12. Tyrophagus putrescentiae (Schrank, 1781) (female): 9. Leg I; 10. Leg II; 11. Leg III; 12. Leg IV.

seta $e 1$; setae $c 1$ the shortest and setae $e 1, f 2, h 2$ the longest dorsal setae; length of dorsal setae: $v i$ 87-100; ve 60-65; sci 180-195; sce 105-115; scx 33-43; c1 32-40; c2 200-220; cp 180-190; d1 95-105; d2 45-50; e1 310-330; e2 225-230; f2 305-320; h1 300-305; h2 315-320. Distances: vi-vi 10-12; vi-ve 37-40; ve-ve 95-98; ve-scx 44-50; scx-scx 135-140; scx-sce 28-32; sce-sce 98-108; sci-sce 30-32; sci-sci 30-40; sci-cl 95-100; c1-c1 123-130; c1-c2 60-68; c2-c2 265-270; c2-cp 40-45; $c p-c p$ 320-330; $c 1-d 1$ $70-75 ; d 1-d 1$ 40-50; d1-d2 118-124; d2-d2 235-250; d2-e2 135-150; d2-gla 70-78; gla-gla 260-280; d2-el 60-65; e1-el 120-130; e1-e2 125-133; e2-e2 260-270; e2-f2 35-48; f2-f2
200-220; e1-h1 140-155; h1-h1 100-110; h1-h2 $25-35 ; h 2-h 2$ 60-75.

Gnathosoma (Figs. 17-18). Punctate; palpi two-segmented, palp tarsus with a simple seta $(p t)$ and one solenidion $(\omega)$ 10-13 and 4-5 long, respectively; palp tibia with two simple setae $(d$ 20-25 and $l 15-20$ long); infracapitulum with one simple seta $(m)$ 30-35 long (Fig. 18); chelicerae 80-90 long, cheliceral seta cha spine like 4-5 long, movable and fixed digits with 3-4 teeth (Fig. 17). Palp coxa with one elcp setae 10 (Fig. 18). Distance: $m-m$ 17-19.

Venter (Figs. 19-20). Coxal plates I divided with apodemes I anteriorly with 5-6 nodes on each side; coxal plates II with a well-developed apodeme 


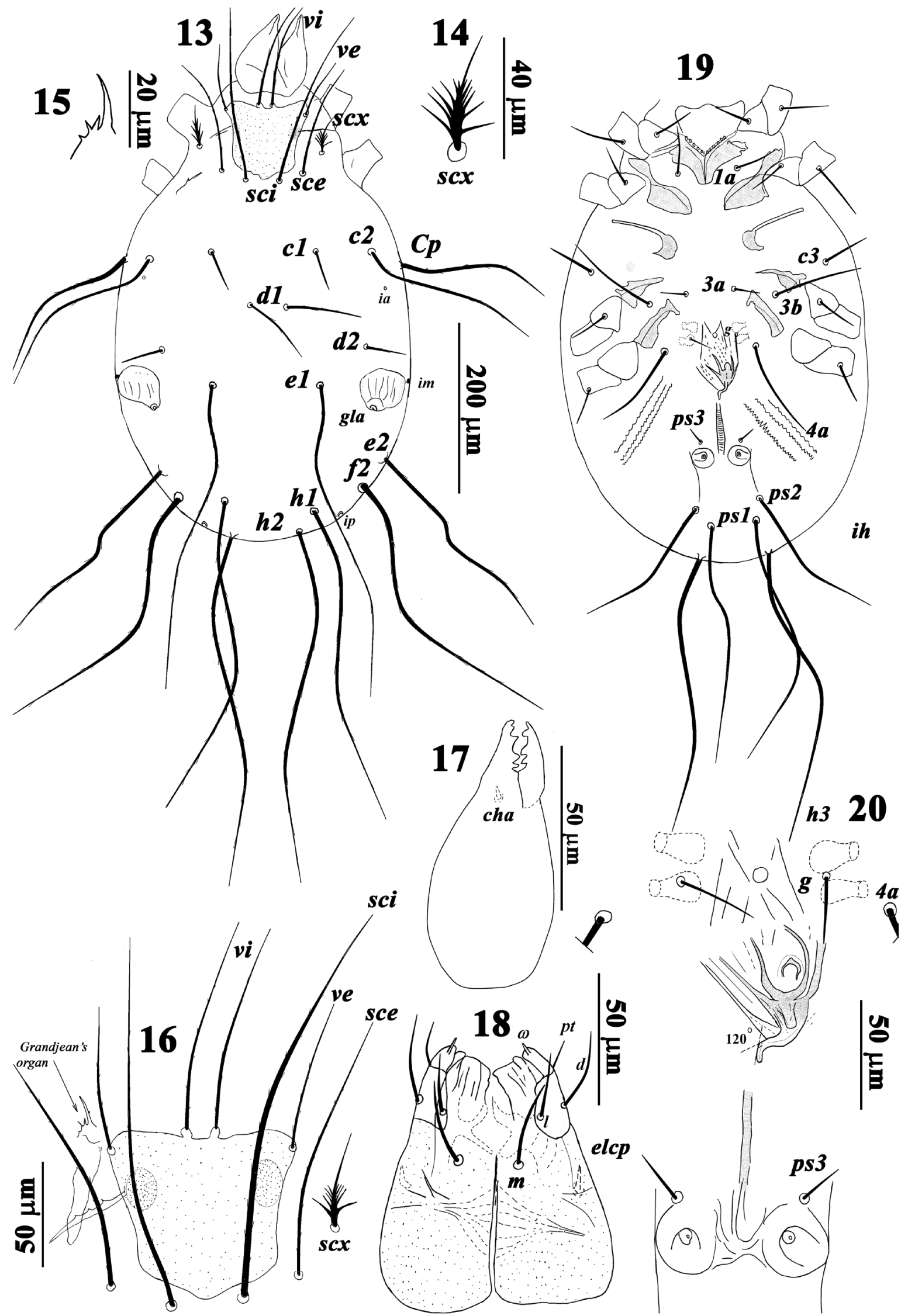

Figures 13-20. Tyrophagus putrescentiae (Schrank, 1781) (male): 13. Dorsal view; 14. Supracoxal seta (scx); 15. Grandjean's organ; 16. Prodorsal shield; 17. Chelicera; 18. Gnathosoma; 19. Ventral view; 20. Genital and anal regions. 
B. A. Fayaz, M. Khanjani and H. Rahmani

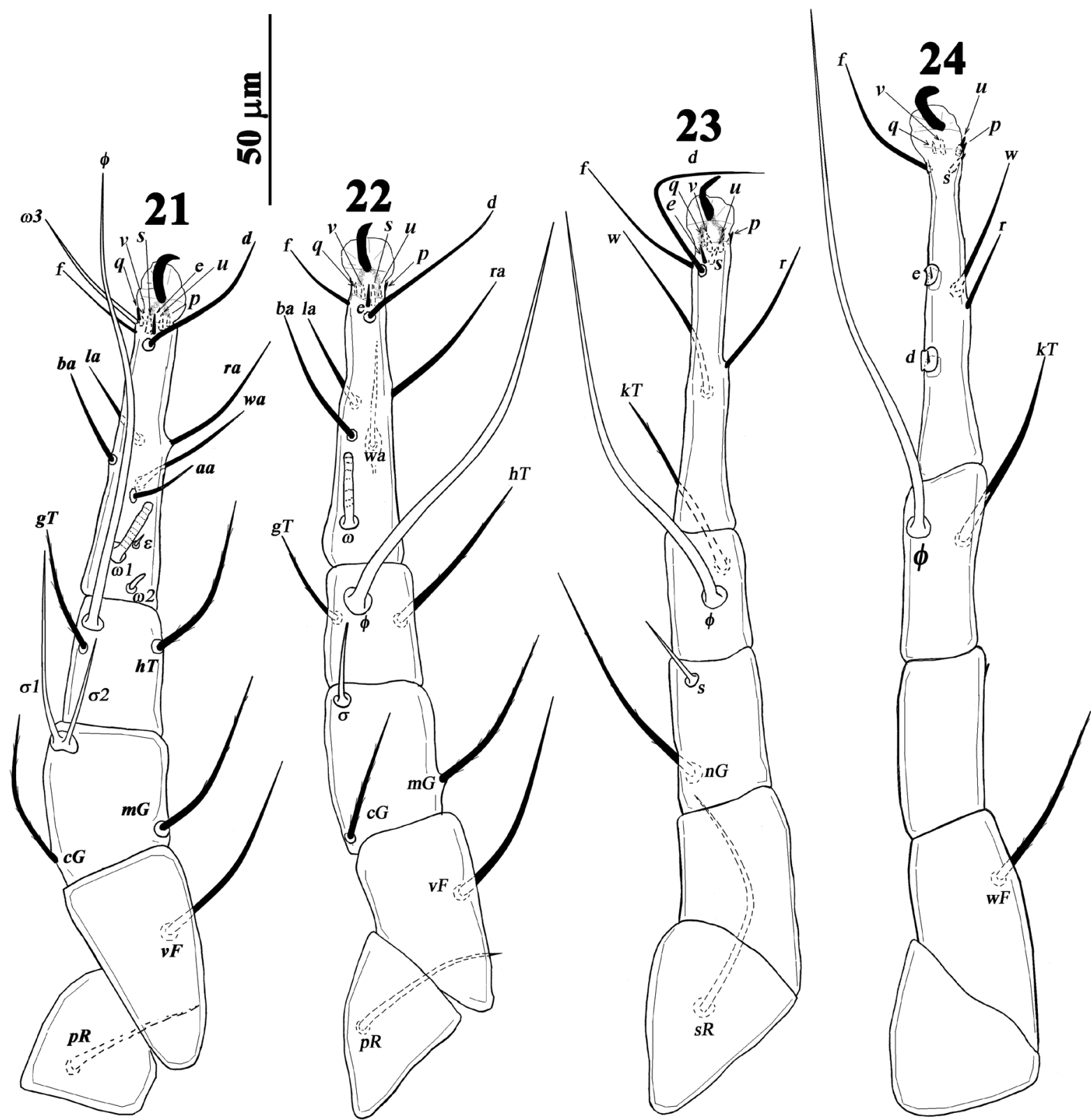

Figures 21-24. Tyrophagus putrescentiae (Schrank, 1781) (male): 21. Leg I; 22. Leg II; 23. Leg III; 24. Leg IV.

near base of trochanter seta; between coxae II and III with a pair of thin sclerotized sejugal apodemes; Coxal plates III-IV each one with apodemes (Fig. 19); genital region (between coxae IV) with two pairs of genital papillae and a pair of setae $(g)$; aedeagus with two obvious curves, S-shaped and distally bent at an angle of $120^{\circ}-125^{\circ}$, aedeagus shaft 23-27 long, lateral arms supporting aedeagus turning out wards (Figs. 19-20). Anal region with three pairs of pseudoanal setae ( $p s 1-3)$, seta $p s 1$ and $p s 3$ the longest and the shortest anal setae respectively, a pair of anal suckers 20-25 and a pair of anal discs 4-5 in diameter (Figs. 19-20); length of ventral setae: $1 a 50-58, c 345-50,3 a 29-33,3 b$ $110-115,4 a 100-105, g$ 30-35, ps3 17-20, ps2 150-165, psl 245-255, h3 295-300. Distances:
$1 a-1 a$ 65-71, 1a-3a 130-135, 3a-3a 55-65, 3a-3b 40-45, g-g 50-65, g-4a 30-34, 4a-4a 100-120, ps1-ps2 20-25, ps2-ps3 70-75, ps2-ps2 60-75, ps1-ps 1 48-53, ps 1-h3 35-40, h3-h3 120-125.

Legs (Figs. 21-24). Setal formulae of leg segments I-IV as follows (solenidia and special setae in parentheses): coxae $1-0-2-1$; trochanters $1-1-$ $1-0$; femora $1-1-0-1$, genua $2(2 \sigma)-2(1 \sigma)-1(1 \sigma)-0$; tibiae $2(1 \varphi)-2(1 \varphi)-1(1 \varphi)-1(1 \varphi)$; tarsi $13(3 \omega$, $1 \varepsilon)-12(1 \omega)-10-10$, solenidion $\omega 1$ cylindrical, with apex slightly widened (figs. 21-24). Measurements of leg segments and setae as follows: Leg I: Tr 35-45, $p R$ 40-44, Fe 50-55, $v F$ 50, Ge 35-40, $c G$ 44-47, $m G$ 48-50, $\sigma 1$ 50-60, $\sigma 2$ 25-28, Ti 30-35, gT 32-35, hT 40-45, 甲 120-130, Ta 70-82, 11

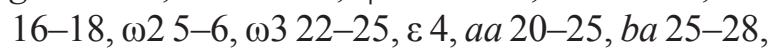



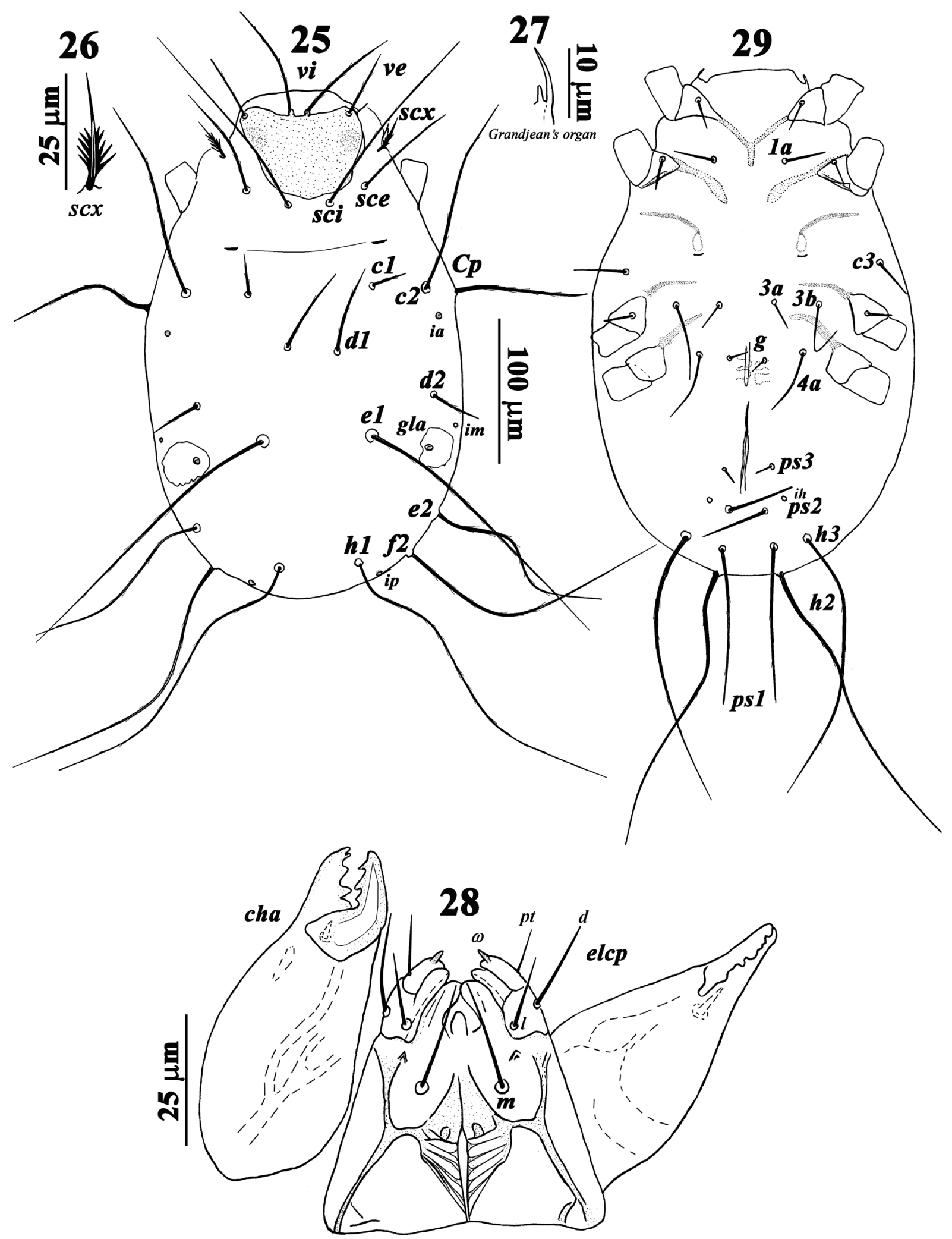

Figures 25-29. Tyrophagus putrescentiae (Schrank, 1781) (tritonymph): 25. Dorsal view; 26. Supracoxal seta (scx); 27. Grandjean's organ; 28. Gnathosoma; 29. Ventral view.

wa 48-52, ra 30-38, la 18-25, d 40-44, e 5-6, f 16-20, $p$ 4, $q$ 4, s-6, $u$ 4-5, v 5, empodium 15-18, claw 10; Leg II: $\operatorname{Tr} 30-40, p R$ 35-40, Fe 48-54, $v F$ 65-70, Ge 35-45, cG 38-40, $m G$ 40-50, $\sigma$ 20-21,
Ti 30, gT 35-40, hT 38-45, $\varphi$ 125-130, Ta 70-78, () 19-20, ba 25-28, wa 42-50, ra 35-40, la 22-23, $d 40-44$, e 5-6, f 15-18, p 3, q 3, s 5-6, u 4, v 4, empodium 15-18, claw 8-10; Leg III: Tr 35-45, 
B. A. Fayaz, M. Khanjani and H. Rahmani

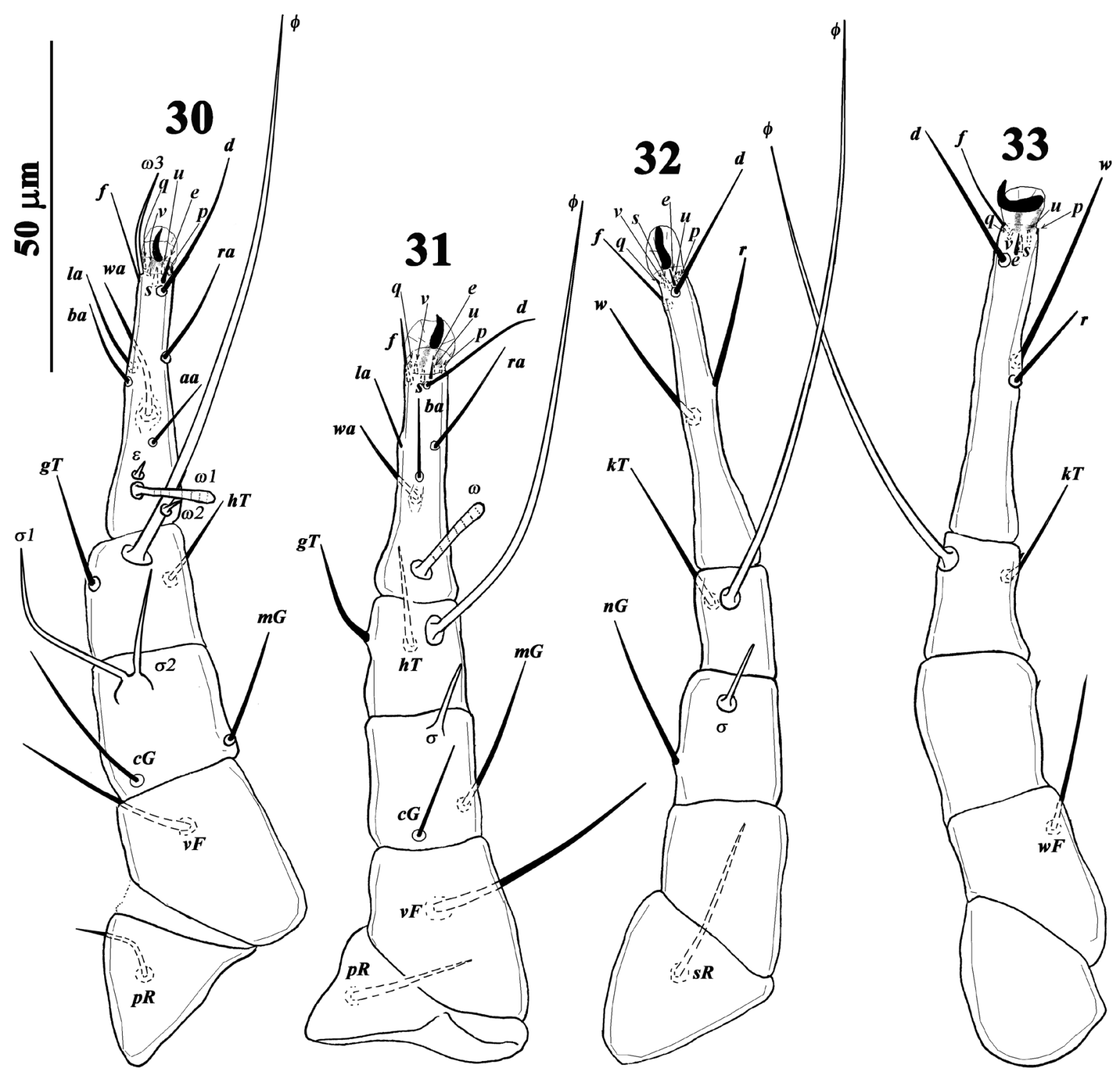

Figures 30-33. Tyrophagus putrescentiae (Schrank, 1781) (tritonymph): 30. Leg I; 31. Leg II; 32. Leg III; 33. Leg IV

$p R 40-54, \mathrm{Fe} 44-50$, Ge 35-40, nG 55-68, $\sigma$ 15-20, Ti 38-40, kT 45-52, $\varphi$ 125-130, Ta 70-75, w 35-40, $r$ 25-30,d 35-38, e 5, f30-35, p 3, q 3, s 5, u 4,v 4-5, empodium 15-20, claw 10; Leg IV: Tr 35-40, $\mathrm{Fe} 45-50$, Ge 40-45, Ti 40, kT 28-32, $\varphi$ 110-115, Ta 78-83, w 42-50, $r$ 18-22, d 3, e 2-3, f 30-38, s 5-7, p 3, q 3, u 4, v 4, empodium 15, claw 9-10. Tarsus IV with two suckers (seta $d$ on proximal and seta $e$ on distal sucker), distance between base of seta $d$ and proximal segment of tarsus 25, $e-d 18-$ 23, e-f 25-28 (Fig. 24) and Ge and Ti IV with minute preapical process (Fig. 24).

Tritonymph (Figs. 25-33; $n=5$ ). Idiosoma oval. Length of body including gnathosoma 410475, excluding gnathosoma $340-410$; width 210 240.
Dorsum (Figs. 25-27). Prodorsal shield punctate, 50-60 long, 65-80 wide between setae ve-ve, nearly pentagonal in shape with lateral margins slightly concave and with two pairs of seta ( $v i$ and $v e$ ); eyespots present on lateral margins of prodorsal shield ( 10-13 in diameter) (Fig. 25); basal lobe of Grandjean's organ with one large tooth and a small teeth, 11-13 and 4 long, respectively (Fig. 27). Supracoxal seta $s c x$ pectinated with five branches on each side (Fig. 26). All dorsal setae finely serrated. All opisthosomal setae whip-like except $c 1, d 1$ and $d 2$. Opisthosoma with three pairs of lyrifissures ( $\mathrm{ia}$, $\mathrm{im}$ and $\mathrm{ip}$ ) and one pair of opisthosomal glands ( $g l a)$ at level of seta $e 1$; seta $c 1$ the shortest and setae $e 1, f 2, h 1$ and $h 2$ the longest dorsal setae; length of dorsal setae: vi 52-60; ve 35-38; sci 120-135; sce 60-63; scx 24-30; c1 
20-25; c2 110-130; cp 85-100; d1 52-60; d2 25; el 180-200; e2 120-130; f2 200-220; h1 180-200; h2 185-230. Distances: vi-vi 8-10; vi-ve 25-30; ve-ve 60-68; ve-scx 30-35; scx-scx 100-120; scx-sce 25-35; sce-sce 80-90; sci-sce 28-30; sci-sci 40-30; sci-cl 66-80; c1-c1 80-95; c1-c2 38-48; $c 2-c 2$ 150-210; $c 2-c p$ 20-35; $c p-c p$ 210-240; $c 1-d 1$ 50-70; d1-d1 30-40; d1-d2 7595; d2-d2 155-180; d2-e2 85-100; d2-gla 38-50; gla-gla 175-230; d2-el 40-60; el-el 80-110; $e 1-e 2$ 65-80; e2-e2 150-180; e2-f2 25-30; f2-f2 120-150; el-h1 85-110; h1-h1 55-70; h1-h2 15-30; h2-h2 40-50.

Gnathosoma (Fig. 28). Palpi two-segmented, palp tarsus with a simple seta $(p t)$ and one solenidion $(\omega) 10$ and 3-4 long, respectively; palp tibia with two simple setae ( $d$ 15-20 and $l 10-11$ long); infracapitulum with one simple seta $(m) 23-25$ long (Fig. 28); chelicerae 60-75 long, cheliceral seta cha spine like 5 long, movable and fixed digits with 4 teeth (Fig. 28). Palp coxa with one elcp setae 7-9 (Fig. 28). Distance: $m-m$ 14-20.

Venter (Fig. 29). Coxal plates I divided with apodemes I narrow and without nodes; coxal plates II with narrow apodemes; a pair of thin sclerotized and narrow sejugal apodemes between coxae II and III; genital region with two pairs of genital papillae and a pair of setae ( $g$ ) (Fig. 29). Anal region with three pairs of pseudoanal setae ( $p s 1-3)$, setae $p s 1$ and $p s 3$ the longest and shortest anal setae, respectively (Fig. 29); a pair of lyrifissures (ih) between setae $p s 2-3$. Length of ventral setae: $1 a$ 28-38, c3 25-30 3a 15-18, 3b 45-52, 4a 44-50, g 15-18, ps3 15-18, ps 2 35-40, ps 1 115-130, h3 170-185. Distances: $1 a-1 a$ 50-55, 1a-3a 95-115, 3a-3a 35-40, 3a-3b 28-40, g-g 18-25, g-4a 28-33, 4a-4a 70-90, ps3-ps3 25-31, ps2-ps2 23-30, ps2-ps1 25-40, ps1-ps1 30-40, ps1-h3 20-30, h3-h3 75-85.

Legs (Figs. 30-33). Setal formulae of leg segments I-IV as follows (solenidia and special setae in parentheses): coxae 1-0-2-1; trochanters $1-$ $1-1-0$; femora $1-1-0-1$, genua $2(2 \sigma)-2(1 \sigma)$ $1(1 \sigma)-0$; tibiae $2(1 \varphi)-2(1 \varphi)-1(1 \varphi)-1(1 \varphi)$; tarsi $13(3 \omega, 1 \varepsilon)-12(1 \omega)-10-10$ (Figs. 30-33). Measurements of leg segments and setae as follows: Leg I: Tr 25-30, $p R$ 17-22, Fe 30-35, $v F$ 30-35, Ge 23-25, $c G$ 18-23, $m G$ 28-30, $\sigma 1$ 25-32, $\sigma 2$ 12-16, Ti 19-23, gT 15-20, hT 18-22, 甲 80-95,

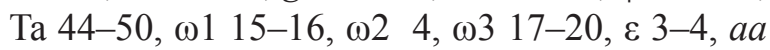
12-15, ba 16-20, wa 20-25, ra 18-20, la 15-18, d 24-30, f 16-20, e 5, p 2-3, q 2-3, s 5-6, u 4, v 4, empodium 10-13, claw 7-10; Leg II: $\operatorname{Tr} 20-25$, $p R$ 18-25, Fe 27-33, $v F$ 35-42, Ge 20-22, $c G$ 12-15, $m G$ 20-24, $\sigma$ 10-12, Ti 18-23, gT 15-20, hT 16-20, $\varphi$ 80-95, Ta 38-40, $\omega$ 14-16, ba 13-17, wa 16-20, ra 22-25, la 14-15, d 25, e 5, f 14-17, p 2-3, q 2-3, s 4-5, u 3-4, v 3-4, empodium 8-10, claw 8-10; Leg III: Tr 25-30, $p R$ 25-30 Fe 25-30, Ge 24-25, nG 27-30, $\sigma$ 10-12, Ti 20-25, kT 28-35, $\varphi$ 90-100, Ta 45-45, w 22-25, r 17-20, d 20-22, $e$ 5, f 15-20, p 2, q 2, s 5, u 3-4,v 3-4, empodium 8-12, claw 5; Leg IV: Tr 25-30, Fe 28-30 Ge 23-28, Ti 25, kT 15-19, $\varphi$ 70-75, Ta 44-50, w 21-25, r 17-20, d 22-25, e 4-5, f 18-22, $p$ 2, q 2, $s 5, u 4, v 4$, empodium 10-12, claw 8-10; Ge and Ti IV with minute preapical process (Fig. 33).

\section{Deutonymph (Hypopus): unknown}

Protonymph (Figs. 34-42; $n=3$ ). Idiosoma oval. Length of body including gnathosoma 310-350, excluding gnathosoma 250-290; width 150-180.

Dorsum (Figs. 34-36). Prodorsal shield and eyespots indistinct and absent, respectively. Basal lobe of Grandjean's organ with one large and one small tooth, 7-8 and 4 long, respectively (Fig. 36). Supracoxal seta $s c x$ pectinated with four branches on each side (Fig. 35). All dorsal setae finely serrated. All opisthosomal setae whip-like except $c 1$, $C p, d 1$ and $d 2$. Opisthosoma with three pairs of lyrifissures ( $\mathrm{ia}$, im and ip) and one pair of opisthosomal gland ( $g l a)$ at level of seta $e 1$; seta $c 1$ the shortest and setae $e 1, f 2, h 1$ and $h 2$ the longest dorsal setae; length of dorsal setae: vi 40-45; ve 25-31; sci 85-92; sce 40-44; scx 21-26; cl 15-18; c2 65-80; Cp 60-70; d1 30-40; d2 17-20; el 125-135; e2 50-68; f2 125-130; h1 135-140; h2 125-135. Distances: vi-vi 6; vi-ve 18-22; ve-ve 40-55; ve-scx 25-30; scx-scx 80-91; scx-sce 20-26; sce-sce 66-75; sci-sce 25; sci-sci 26-28; $s c i-c 1$ 50-58; $c 1-c 1$ 65-75; $c 1-c 2$ 25-31; $c 2-c 2$ 125-135; c2-Cp 18-25; Cp-Cp 150-180; c1-d1 35-40; d1-d1 25-30; d1-d2 46-55; d2-d2 110125; d2-e2 60-68; d2-gla 25-33; gla-gla 118-125; d2-e1 31-37; e1-e1 58-65; e1-e2 48-55; e2-e2 110-127; e2-f2 18-20;f2-f2 95-110; e1-h1 60-70; $h 1-h 1$ 40-50; h1-h2 10; h2-h2 25-38.

Gnathosoma (Fig. 37). Palpi two-segmented, palp tarsus with a simple seta $(p t)$ and one solenidion $(\omega)$ 7-8 and 3 long, respectively; palp tibia with two simple setae ( $d$ 14-16 and $l$ 7-8 long); infracapitulum with one simple seta $(m) 12-15$ long (Fig. 37); chelicerae 50 long, cheliceral seta cha spine like 3 long. Palp coxa with one elcp setae 5-7. Distance: $m-m$ 15-22.

Venter (Fig. 38). Coxal plates and apodemes I strongly reduced; coxal plates II with narrow 
B. A. Fayaz, M. Khanjani and H. Rahmani

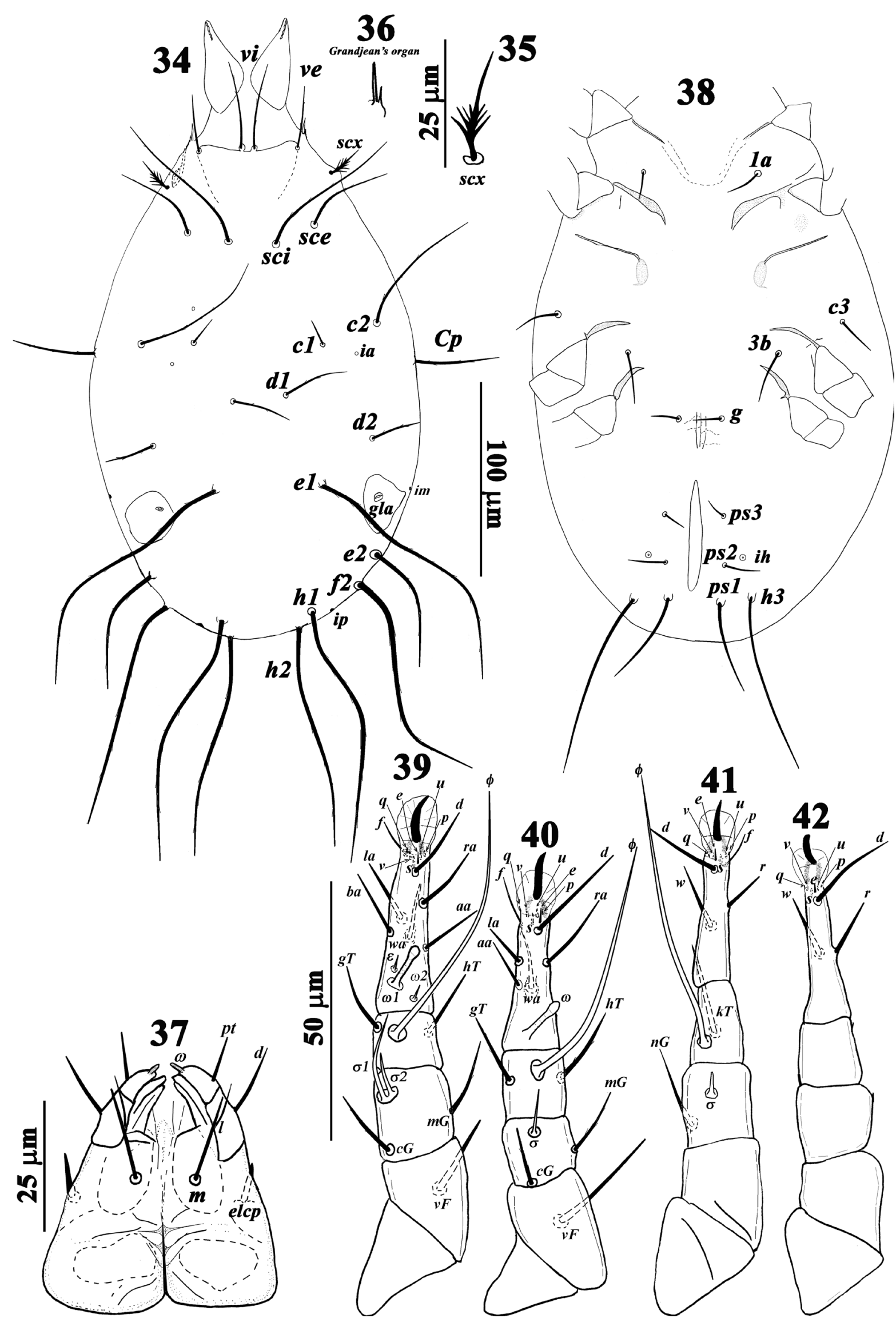

Figures 34-42. Tyrophagus putrescentiae (Schrank, 1781) (protonymph): 34. Dorsal view; 35. Supracoxal seta $(s c x)$; 36. Grandjean's organ; 37. Gnathosoma; 38. Ventral view; 39. Leg I; 40. Leg II; 41. Leg III; 42. Leg IV. 
apodemes; a pair of thin sclerotized and narrow sejugal apodemes between coxae II and III; genital region with one pair of genital papillae, a pair of setae $(g)$ (Fig. 38). Anal region with three pairs of pseudoanal setae ( $p s 1-3)$, seta $p s 1$ the longest anal seta (Fig. 38); a pair of lyrifissures (ih) between setae $p s 2-3$. Length of ventral setae: 1 a 20-25, $3 b$ 28-35, c3 20-25, g 10-14, ps3 10-13, ps2 16-18, psl 50-52, h3 105-125. Distances: $1 a-1 a$ 45-60, $1 a-3 b$ 82-90, 3b-3b 60-75 3b-c3 30-38, g-g 18-20, ps3-ps3 20-30, ps2-ps2 20-28, ps2-ps1 18-20, ps1-ps1 22-27, ps1-h3 16-20, h3-h3 61-70.

Legs (Figs. 39-42). Setal formulae of leg segments I-IV as follows (solenidia and special setae in parentheses): coxae $1-0-1-0$; trochanters 0 $0-0-0$; femora $1-1-0-0$, genua $2(2 \sigma)-2(1 \sigma)$ $1(1 \sigma)-0$; tibiae $2(1 \varphi)-2(1 \varphi)-1(1 \varphi)-0$; tarsi 13 $(2 \omega, 1 \varepsilon)-12(1 \omega)-10-9$ (figs. 39-42). Measurements of leg segments and setae as follows: Leg I: Tr 15-20, Fe 25-29, vF 18-25, Ge 15-18, $c G$ 13-14, $m G$ 14-16, б1 17-20, б2 7-10, Ti 15-17,

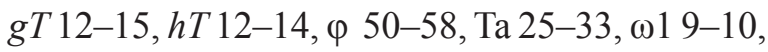
(2) 3-4, \& 2-3, a a 10-12, ba 14, wa 20, ra 17-18, la 12-15, $d$ 20-24, e 4, f11-13, $p$ and $q 2-3, s 4$, $v$ and $u$ 3-4, empodium 10-11, claw 6-7; Leg II: Tr 18-25, Fe 25-33, vF 25-30, Ge 14-16, cG 12-14, $m G$ 15-20, o 7-9, Ti 13-15, gT 13-14, hT

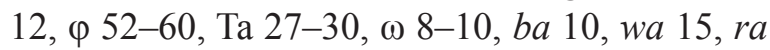
15-20, la 10-12, $d 17-20, e 4, f 8-10, p$ and $q 2-3$, $s 4, v$ and $u$ 3-4, empodium 10, claw 7-8; Leg III: Tr 20-24, Fe 18-20, Ge 15-20, nG 18-20, 。 4-6, Ti 15, kT 14-18, $\varphi$ 55-70, Ta 28-36, w 15, r 10-12, $d$ 15-18, e 4, f 8-10, $p$ and $q 2, s 3-4, v$ and $u$ 3, empodium 10, claw 8; Leg IV: Tr 25, Fe 15-20, Ge 15-18, Ti 15-17, Ta 30-35, w 14-17, $r$ 8-11, $d 13$, $e 3, p$ and $q 1-2, s 3, v$ and $u 2$, empodium 8 , claw 6 ; Ge and Ti IV with minute preapical process (fig. 42).

Larva (Figs. 43-51; $n=5$ ). Idiosoma oval. Length of body including gnathosoma 220-290, excluding gnathosoma 180-235; width 120-150.

Dorsum (Figs. 43-45). Prodorsal shield and eyespots indistinct. Basal lobe of Grandjean's organ finger-like and with one large and one small tooth, 5-7 and 2 long, respectively (Fig. 45). Supracoxal seta $s c x$ pectinated with three branches on each side (Fig. 44). All dorsal setae finely serrated. Opisthosomal setae $e 1, h 1$ whip-like. Setae $f 2$ and $h 3$ absent. Opisthosoma with one pair of opisthosomal glands ( $g l a)$ at level of seta $e 1$; setae $d 2$ and $c 1$ the shortest and seta $h l$ the longest dorsal setae; length of dorsal setae: vi 27-30; ve 15-20; sci 48-55; sce 20-25; scx 10-18; c1 12-15; c2 30-37; Cp 35-42; d1 20-25; d2 11-13; el 80-85; e2 14-18; h1 105-125; h2 45-60. Distances: vi-vi 5; vi-ve 1220; ve-ve 35-45; ve-scx 20-25; scx-scx 65-75; scx-sce 20-25; sce-sce 55-75; sci-sce 20-25; sci-sci 20-25; sci-cl 35-55; c1-c1 55-70; c1-c2 18-27; $c 2-c 2$ 88-120; $c 2-C p$ 15-20; $C p-C p$ 100-135; c1-d1 25-30; d1-d1 20-26; d1-d2 3545 ; d2-d2 80-115; d2-e2 40-55; d2-gla 20-25; gla-gla 90-112; d2-e1 25-35; e1-el 40-50; e1-e2 35-50; e2-e2 80-100; e1-h1 44-53; h1-h1 44-50; $h 1-h 2$ 17-25; h2-h2 11-17.

Gnathosoma (Figs. 46-47). Palpi two-segmented, palp tarsus with a simple seta $(p t)$ and one solenidion ( $\omega$ ) 5-8 and 2-3 long, respectively; palp tibia with two simple setae $(d \quad 10-12$ and $l 7-8$ long); infracapitulum with one simple seta $(m)$ 15-18 long (fig. 47); chelicerae 35-40 long, cheliceral seta cha spine like 2 long, movable and fixed digits with 3-5 teeth (fig. 46). Palp coxa with one elcp seta 5. Distance: $m-m$ 10-11.

Venter (Fig. 48). Coxal plates I-III with narrow apodemes; Claparède organ, between coxae I-II, with base tube-like and 16-20 in length terminating in a spherical knob distally, 3-4 in diameter), setae $3 a, 4 a$, genital papillae and seta, adanal and pseudoanal setae absent; a pair of lyrifissures (ih) anterolateral of setae $h 2$. Length of ventral setae: la 14-15, $3 b$ 20, c3 17-20. Distances: 1a-1a $25-35,1 a-3 b$ 65-80, 3b-3b 35-55, 3b-c3 3145 .

Legs (Figs. 49-51). Setal formulae of leg segments I-IV as follows (solenidia and special setae in parentheses): coxae $1-0-1$; trochanters $0-0-0$; femora $1-1-0$, genua $2(2 \sigma)-2(1 \sigma)-1(1 \sigma)$; tibiae $2(1 \varphi)-2(1 \varphi)-1(1 \varphi)$; tarsi $13(1 \omega, 1 \varepsilon)-12(1 \omega)-10$ (Figs. 49-51). Measurements of leg segments and setae as follows: Leg I: Tr 14-16, Fe 20-17, $v F$ 17-20, Ge 13-15, cG 9-11, $m$ G 12-15, o1 12-15, б2 5-6, Ti 11-13, gT 11-13, hT 8-10, ф 50-55, Ta 25-29, w1 8-10, ع 3-4, a a 7-11, ba 7-11, wa 10-13, ra 11-13, la 8-11, d 17-20, e 3, f 8-11, q and $p 2, s 2-3, v$ and $u 2-3$, empodium 5-7, claw 3-4; Leg II: Tr 13-15, Fe 18-21, vF 17-20, Ge 13-15, cG 11-15, mG 8-10, o 4-5, Ti 10-11, gT 10-11, hT 9-11, $\varphi$ 44-52, Ta 18-24, $\omega$ 5-7, ba 7-11, wa 11-13, ra 8-10, la 8-10, d 14-17, e 3, f 6-8, $q$ and $p 1-2, s 2, v$ and $u 2$, empodium 8-10, claw 5-7; Leg III: Tr 15-17, Fe 15-18, Ge 11-12, $n G$ 18-20, $\sigma$ 4-6, Ti 13-15, kT 13-15, $\varphi$ 48-60, Ta 26-30, w 10-13, r 10-12, d 16-18, e 3, f11-13, q 
B. A. Fayaz, M. Khanjani and H. Rahmani

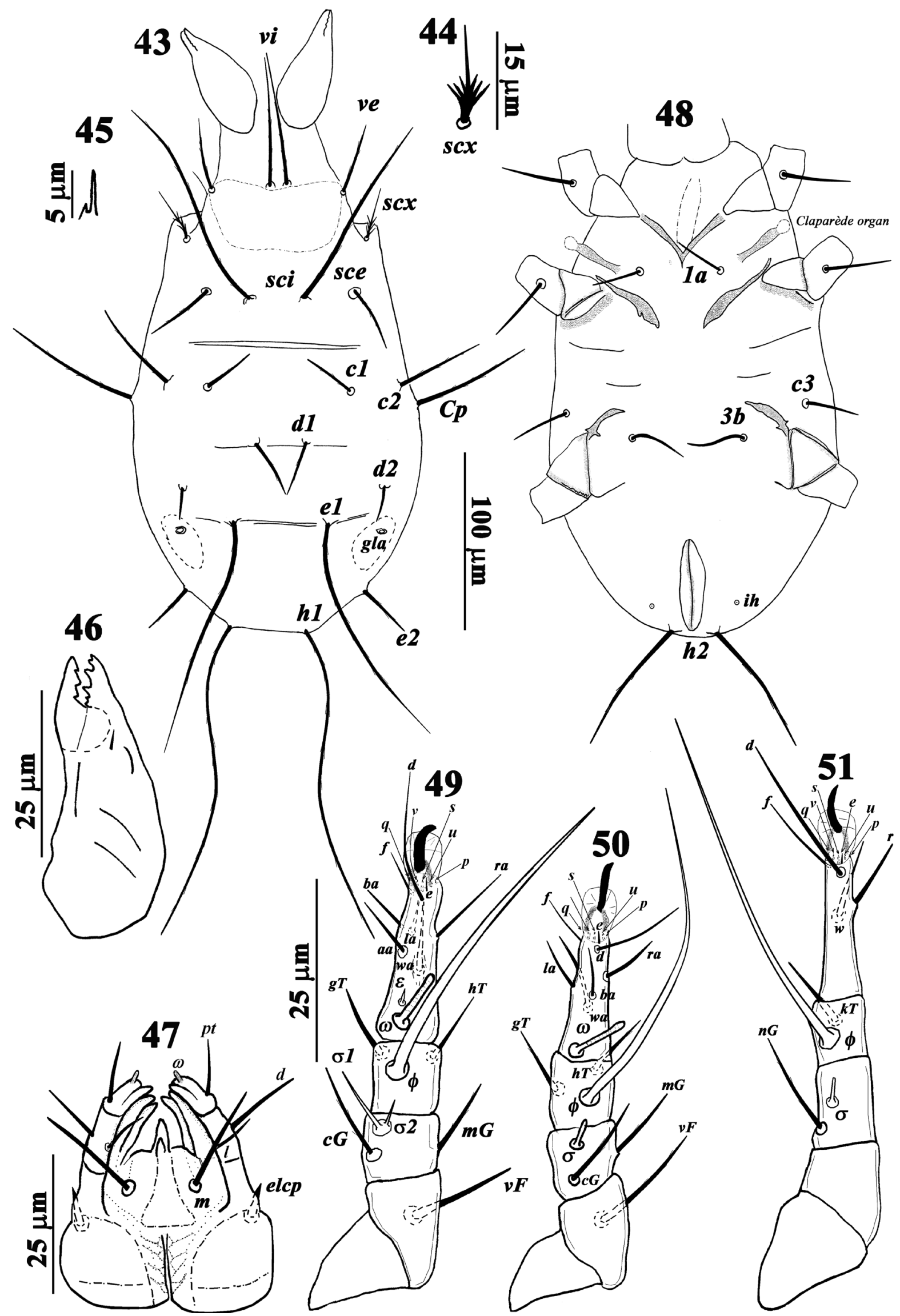

Figures 43-51. Tyrophagus putrescentiae (Schrank, 1781) (larva): 43. Dorsal view; 44. Supracoxal seta (scx); 45. Grandjean's organ; 46. Chelicera; 47. Gnathosoma; 48. Ventral view; 49. Leg I; 50. Leg II; 51. Leg III. 


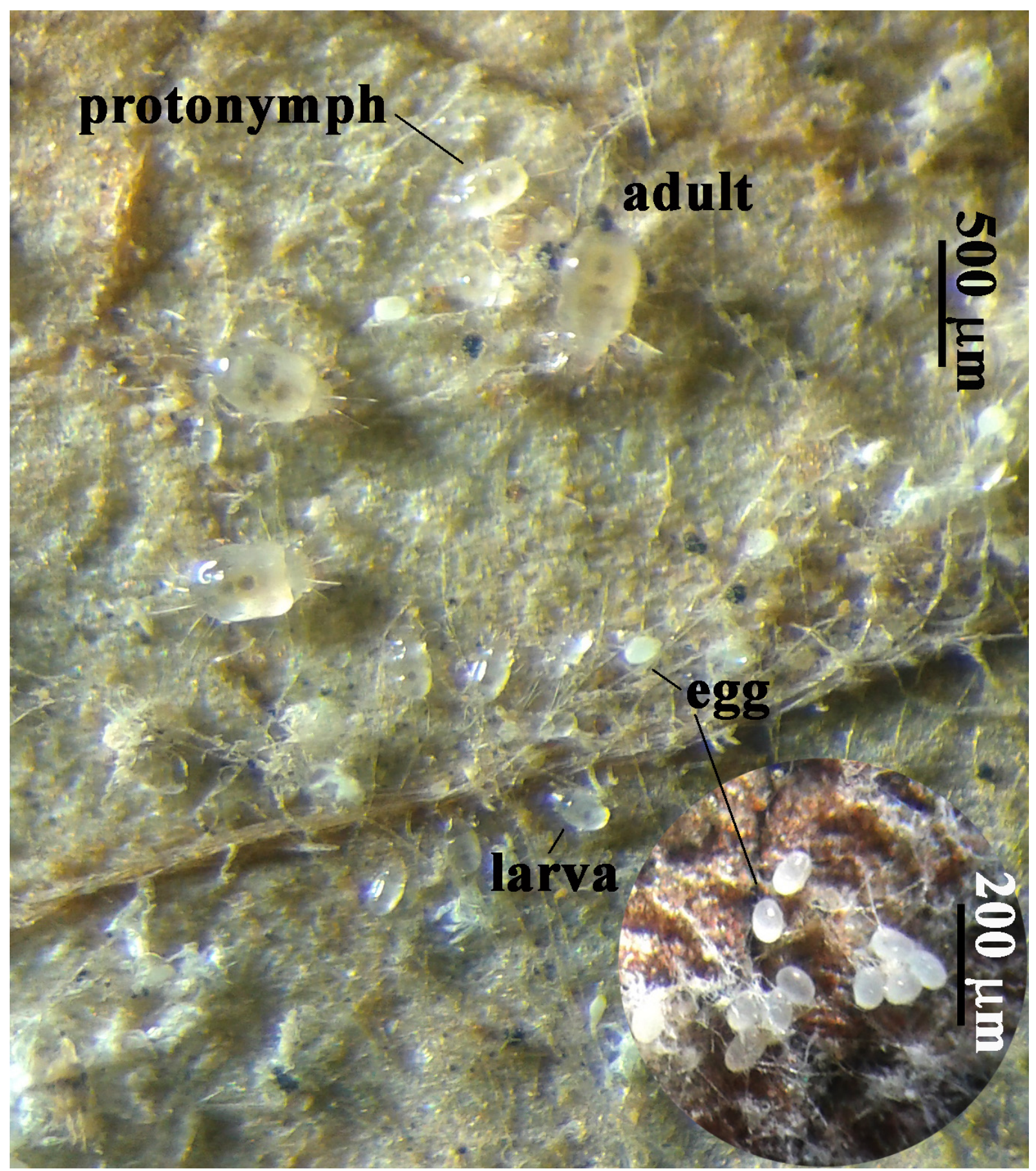

Figure 52. Tyrophagus putrescentiae (Schrank, 1781): egg, larva, protonymph and adult

and $p 1, s 2, v$ and $u 1-2$, empodium 10, claw 6 long.

Egg (Fig. 52). White and oval in shape, 125140 long $\times$ 80-90 wide (Fig. 52).

\section{DISCUSSION \& CONCLUSION}

We redescribed developmental stages of $T$. putrescentiae based on specimens from Iran. $T$. putrescentiae mites are important as pests contaminating food with fungi, causes of allergens, and an alternative prey or food source for mass rearing of predatory mites used in biological control (Huang et al. 2013). This redescription demostrates minor differences between Iranian specimens and a recent redescription from New Zealand (Fan and Zhang 2007) but differs as follows: (Female): 1. Measurements and distances of dorsal seta $c l$ 30-42; c2 210-230; c3 30-35; h1 320-360; h3 280-300; d2-gla 65-82 in Iranian specimens opposed to $c 150-51 ; c 2$ 247- 261; c3 47-49; hl 384-392; h3 314-319; d2-gla 48-51 in New Zealand specimens; (Male): 1. Prodorsal shield 90-100 
wide between setae ve-ve versus $68-77 ; 2$. vi/ve $=1.45-1.54$ vs. $1.8-2.3 ; 3$. Measurements of setae ve 60-65; cp 180-190; ps1 245-255; ps 2 150-165; I $\phi$ 120-130; II $\phi 125-130$ vs. ve 44-46, $c p$ 141151; ps1 178-181; ps2 81-106; I $\phi$ 81-108, II $\phi$ 102-115. Furthermore this redescription closely resembles a redescription by Klimov and OConnor (2009) in having distal one-third of aedeagus (bent at an angle more than $110^{\circ}$ ); pattern of coxal sclerotization II; shape of solenidion I $\omega 1$; also genu and tibia IV with small preapical processes in all mobile stages (except larvae) according to other redescriptions from Spain (Jorrín-Novo et al. 2003). The discriminative characters of immature and adult stages of this species are listed in Table 1.

\section{Key to Iranian Tyrophagus species (modified from Samšinák 1962 and Fan and Zhang 2007)}

1. Dorsal seta $d l$ sub equal to seta $c l$ in length .... .2

- Dorsal seta $d 1$ 1.5-3 times longer than seta $c 1$ in length 3

2. Supracoxal seta $(s c x)$ short (less than $20 \mu \mathrm{m})$ and almost smooth; lateral arms supporting aedeagus turning out wards ....

T. brevicrinatus Robertson, 1959

- Supracoxal seta ( $s c x)$ slender and with pectination (40-50 $\mu \mathrm{m}$ long); lateral arms supporting aedeagus turning inwards .....T. similis Volgin, 1949 3. Eyespots present. ... 4

- Eyespots absent .5

4. Penis S-shaped

T. putrescentiae (Schrank, 1781)

- Penis not distinctly S-shaped.... ..T. neiswanderi Johnston and Bruce, 1965
5. Dorsal seta $d l$ considerably longer than seta $c l$, 2.4-3.2 times 6 — Dorsal seta $d 1$ at most twice as long as seta $c 1$

6. Supracoxal seta $s c x$ slender; spermathecal duct cylindrical shaped............... T. vanheurni Oudemans, 1924b [ $=$ T. palmarum Oudemans; sensu Robertson, 1959 (Fan and Zhang, 2007)] - Supracoxal seta $s c x$ tapering from base to tip or slightly widened in basal 2/3; spermathecal duct very wide along its entire length

T. perniciosus Zakhvatkin, 1941

7. Solenidion I $\omega 1$ tapered distally and cylindrical shaped .T. longior (Gervais, 1844) — Solenidion I $\omega 1$ not tapered distally. T. zachvatkini Volgin, 1948

\section{ACKNOWLEDGEMENTS}

The authors are very grateful to Dr. Pavel B. Klimov (Department of Ecology and Evolutionary Biology, University of Michigan, Ann Arbor, USA; Tyumen State University, Tyumen, Russia); Prof. Edward A. Ueckermann (School of Environmental Sciences and Development, North-West University, Potchefstroom, South Africa; ARC-Plant Protection Research Institute, Queenswood, Pretoria, South Africa), and Prof. Qing-Hai Fan (Plant Health and Environment Laboratory, Ministry for Primary Industries, Auckland, New Zealand) for their critical review and providing valuable suggestions to the draft of this manuscript and supplying some literatures. The $\mathrm{PhD}$ research of the senior author was financially supported by the Vice Chancellor for Research of Bu-Ali Sina University, Hamedan, Iran.

Table 1. Idiosomal and leg chaetotaxy, and organotaxy status of T. putrescentiae (Schrank) in mobile stages.

\begin{tabular}{|c|c|c|c|c|c|}
\hline Character / Stage & Larva & Protonymph & Tritonymph & Adult (Female) & Adult (Male) \\
\hline$v i$ & + & + & + & + & + \\
\hline ve & + & + & + & + & + \\
\hline sci & + & + & + & + & + \\
\hline sce & + & + & + & + & + \\
\hline $\operatorname{scx}$ & + & + & + & + & + \\
\hline$c 1$ & + & + & + & + & + \\
\hline$c 2$ & + & + & + & + & + \\
\hline$c 3$ & + & + & + & + & + \\
\hline
\end{tabular}


Tyrophagus putrescentiae from Western Iran

\begin{tabular}{|c|c|c|c|c|c|}
\hline$C p$ & + & + & + & + & + \\
\hline$d 1$ & + & + & + & + & + \\
\hline$d 2$ & + & + & + & + & + \\
\hline$e 1$ & + & + & + & + & + \\
\hline$e 2$ & + & + & + & + & + \\
\hline$f 2$ & - & + & + & + & + \\
\hline$h 1$ & + & + & + & + & + \\
\hline$h 2$ & + & + & + & + & + \\
\hline$h 3$ & - & + & + & + & + \\
\hline Grandjean's organ & + & + & + & + & + \\
\hline $1 a$ & + & + & + & + & + \\
\hline $3 a$ & - & - & + & + & + \\
\hline $3 b$ & + & + & + & + & + \\
\hline $4 a$ & - & - & + & + & + \\
\hline$g$ & - & - & + & + & + \\
\hline$a d 1$ & - & - & - & - & + \\
\hline$a d 2$ & - & - & - & - & + \\
\hline ad3 & - & - & - & - & + \\
\hline ps1 & - & + & + & + & + \\
\hline ps 2 & - & + & + & + & + \\
\hline ps3 & - & + & + & + & + \\
\hline Genital papillae & - & + (1 pair) & $+(2$ pairs $)$ & $+(2$ pairs $)$ & $+(2$ pairs $)$ \\
\hline Opisthosomal gland (gla) & + & + & + & + & + \\
\hline Copulatory opening & - & - & - & - & + \\
\hline Spermatheca & - & - & - & - & + \\
\hline Aedeagus & - & - & - & + & - \\
\hline Anal suckers & - & - & - & + & - \\
\hline Claparède organ & + & - & - & - & - \\
\hline Leg IV & - & + & + & + & + \\
\hline Cx. I-III or IV & $1-0-1$ & $1-0-1-0$ & $1-0-2-1$ & $1-0-2-1$ & $1-0-2-1$ \\
\hline Tr. I-III or IV & $0-0-0$ & $0-0-0-0$ & $1-1-1-0$ & $1-1-1-0$ & $1-1-1-0$ \\
\hline Fe. I-III or IV & $1-1-0$ & $1-1-0-0$ & $1-1-0-1$ & $1-1-0-1$ & $1-1-0-1$ \\
\hline Ge. I-III or IV & $\begin{array}{c}2(2 \sigma)-2(1 \sigma)- \\
1(1 \sigma)\end{array}$ & $\begin{array}{c}2(2 \sigma)-2(1 \sigma)- \\
1(1 \sigma)-0\end{array}$ & $\begin{array}{c}2(2 \sigma)-2(1 \sigma)- \\
1(1 \sigma)-0\end{array}$ & $\begin{array}{c}2(2 \sigma)-2(1 \sigma)- \\
1(1 \sigma)-0\end{array}$ & $\begin{array}{c}2(2 \sigma)-2(1 \sigma)- \\
1(1 \sigma)-0\end{array}$ \\
\hline Ti. I-III or IV & $\begin{array}{c}2(1 \varphi)-2 \\
(1 \varphi)-1(1 \varphi)\end{array}$ & $\begin{array}{c}2(1 \varphi)-2 \\
(1 \varphi)-1(1 \varphi)-0\end{array}$ & $\begin{array}{c}2(1 \varphi)-2(1 \varphi)-1 \\
(1 \varphi)-1(1 \varphi)\end{array}$ & $\begin{array}{c}2(1 \varphi)-2(1 \varphi)-1 \\
(1 \varphi)-1(1 \varphi)\end{array}$ & $\begin{array}{c}2(1 \varphi)-2(1 \varphi)-1 \\
(1 \varphi)-1(1 \varphi)\end{array}$ \\
\hline Ta. I-III or IV & $\begin{array}{c}13(1 \omega, 1 \varepsilon)-12 \\
(1 \omega)-10\end{array}$ & $\begin{array}{c}13(2 \omega, 1 \varepsilon)-12 \\
(1 \omega)-10-9\end{array}$ & $\begin{array}{c}13(3 \omega, 1 \varepsilon)-12 \\
(1 \omega)-10-10\end{array}$ & $\begin{array}{c}13(3 \omega, 1 \varepsilon)-12 \\
(1 \omega)-10-10\end{array}$ & $\begin{array}{c}13(3 \omega, 1 \varepsilon)-12 \\
(1 \omega)-10-10\end{array}$ \\
\hline Ta. IV with suckers & - & - & - & - & + \\
\hline
\end{tabular}




\section{REFERENCES}

Chmielewski, W. 1999. Acceptance of buckwheat grain as a food by Tyrophagus putrescentiae (Schr.) (Acari: Acaridae). Fagopyrum, 16: 95-97.

Fan, Q.-H., Zhang, Z.-Q. 2007. Tyrophagus (Acari: Astigmata: Acaridae). Fauna of New Zealand, 56: $291 \mathrm{pp}$.

Fan, Q.-H.; Zhang, Z.-Q. 2014. Case 3501. Comment on the proposed conservation of usage by designation of a replacement neotype for Acarus putrescentiae Schrank, 1781 (currently Tyrophagus putrescentiae; Acariformes, Acaridae). Bulletin of Zoological Nomenclature, 71(2): 99-102.

Gervais, F. L. P. 1844. Acarides. In: Walckenaer's Histoire Naturelle des Insectes. Aptères. 3: 260266.

Grandjean, F. 1939. La chaetotaxie des pattes chez les Acaridae. Bulletin de la Société Zoologique de France, 64: 50-60.

Griffiths, D. A.; Atyeo, W. T.; Norton, R. A.; Lynch, C. A. 1990. The idiosomal chaetotaxy of astigmatid mites. Journal of Zoology, London, 220: 1-32.

Hadad Iraninezhad, K., Rahgozar, M. and Valizadeh, M. 2007. [Astigmatic mite fauna of alfalfa fields and their distribution in South West of East Azerbaijan Province]. Journal of Agricultural Science, 17(1): 127-137. [In Persian with English abstract]

Huang, H., Xu, X., Lv, J., Li, G., Wang, E. and Gao, Y. 2013. Impact of proteins and saccharides on mass production of Tyrophagus putrescentiae (Acari: Acaridae) and its predator Neoseiulus barkeri (Acari: Phytoseiidae). Biocontrol Science and Technology, 23(11): 1231-1244.

Jorrín-Novo, J., Acosta-García, M. I. and Vargas-Piqueras, P. (2003) Morphometry and intrapopulational variability of Tyrophagus putrescentiae (Acari, Acaridae). Acarologia, 43(3): 307-322.

Johnston, D. E., Bruce, W. A. 1965. Tyrophagus neiswanderi, a new acarid mite of agricultural importance. Research Bulletin of Ohio Agricultural Experimental Station, 977: 1-17.

Kamali, K., Ostovan, H., Atameh, A. 2001. A Catalog of Mites \& Ticks (Acari) of Iran. Islamic Azad University Scientific Publication Center, 196 pp.

Khanjani, M., Kamali, K., Mosaddegh, M.S. 2000. The Acari fauna of Astigmata of legumes in Hamadan, Iran. The Journal of Agricultural Science, 9(4): 27-41.

Klimov, P.B. and OConnor, B.M. 2003. Phylogeny, historical ecology and systematics of some mush- room-associated mites of the genus Sancassania (Acari: Acaridae), with new generic synonymies. Invertebrate Systematics, 17: 469-514.

Klimov, P. B., OConnor, B. M. 2009. Conservation of the name Tyrophagus putrescentiae, a medically and economically important mite species (Acari: Acaridae). International Journal of Acarology, 35 (2): 95-114.

Klimov, P. B., OConnor, B. M. 2010. Case 3501. Acarus putrescentiae Schrank, 1781 (currently Tyrophagus putrescentiae; Acariformes, Acaridae): proposed conservation of usage by designation of a replacement neotype. Bulletin of Zoological Nomenclature, 67(1): 24-27.

Lotfollahi, P., Hadad Irani-Nejad, K., Bagheri, M., Valizadeh, M. 2010. [Astigmatic soil mite fauna of Alfalfa fields: record of two new mites of the family Histiostomatidae and their distribution in North-West of East Azerbaijan Province]. Journal of Plant Protection, 24(3): 303-314. [In Persian]

Oudemans, A.C. 1924a. Acarologische Aanteekeningen LXXIV. Entomologische Berichten, 136(VI): 241-260.

Oudemans, A.C. 1924b. Acarologische Aanteekeningen LXXVII. Entomologische Berichten 136(VI): 317-336.

Robertson, P. L. 1959. A revision of the genus $T y$ rophagus, with a discussion on its taxonomic position in the Acarina. Australian Journal of Zoology, 7(2): 146-181.

Samšinák, K. 1962. Beiträge zur Kenntnis der Gattung Tyrophagus Oudemans. Acta Societatis Entomologicae Čechosloveniae, 59(3): 266280.

Schrank, F. P. 1781. Enumeratio Insectorum Austriae Indigenorum. August Vindelicor, Klett, 548 pp.

Volgin, V. I. 1948. [New species of mites of the genus Tyrophagus Ouds., 1923 (Tyroglyphidae, Acarina)]. Doklady Akademii Nauk USSR, Zoology, LX (3): 509-511. [In Russian]

Volgin, V. I. 1949. Materials on systematics of mites of the genus Tyrophagus Ouds., 1923 (Tyroglyphidae, Acarina). Doklady Akademii Nauk USSR, Zoology, 65(3): 385-388.

Zakhvatkin, A. A. 1941, Fauna of U.S.S.R. Arachnoidea. Vol. VI, No. 1: Tyroglyphoidea [Acari]. American Institute of Biological Sciences, Washington DC. 573 pp. (Translation from Russian by Ratcliffe, A.; Hughes, A. M., 1959). 